\title{
A stiffened plate buckling model for calculating critical stress of distortional buckling of CFS beams
}

\section{Li, Long-yuan}

http://hdl.handle.net/10026.1/5277

10.1016/j.jimecsci.2016.07.023

International Journal of Mechanical Sciences

Elsevier

All content in PEARL is protected by copyright law. Author manuscripts are made available in accordance with publisher policies. Please cite only the published version using the details provided on the item record or document. In the absence of an open licence (e.g. Creative Commons), permissions for further reuse of content should be sought from the publisher or author. 
To be published in - International Journal of Mechanical Science

(http://dx.doi.org/10.1016/j.ijmecsci.2016.07.023)

Paper was submitted on 19/05/2016 and accepted on 19/07/2016

\title{
A stiffened-plate buckling model for calculating critical stress of distortional buckling of CFS beams
}

Jue Zhu (zhujue@nbu.edu.cn) ${ }^{1}$ and Long-yuan Li (long-yuan.li@plymouth.ac.uk) ${ }^{2}$

(1) Faculty of Mechanical Engineering and Mechanics, Ningbo University, China

(2) School of Marine Science and Engineering, University of Plymouth, UK

\begin{abstract}
This paper presents a novel stiffened plate buckling model for describing the distortional buckling of cold-formed steel zed- and channel-section beams when they are bent about their major axis. In the model the compression flange and lip together with the web are treated as a plate with an angle stiffener. By using the classical principle of total potential energy, an analytical expression for the critical buckling stress of the stiffened plate is obtained. In order to validate the present model, finite strip analysis is also carried out for 59 CFS channel-section beams used in the UK market. The comparison of the critical stresses calculated from the present stiffened plate buckling model and those obtained from the finite strip analysis demonstrates that the present model provides an excellent prediction for the critical stress of distortional buckling of CFS section beams.
\end{abstract}

Keywords: Cold-formed steel, beams, distortional buckling, modelling, analytical solution

\section{Introduction}

Thin-walled, cold-formed steel (CFS) sections have been widely used as purlins and rails in buildings for farming and industrial use. These sections, when subjected to compression and/or bending, may undergo a mode of buckling called distortional, which involves a rotation of the lip/flange component about the flange/web corner with a half-wavelength that is greater than that of local buckling mode but much shorter than the member length. Unlike the local and lateral-torsional bucklings which have been well-defined and can be analysed using the classical theories of plates and beams, the distortional buckling is not fully recognised and its analysis is rather complicated.

Distortional buckling was first discovered by Hancock in 1978 [1], who investigated the local, distortional, and flexural-torsional modes of buckling of I-beams bent about their major axis by using the finite strip method. However, as far as the CFS section is concerned, the analysis of distortional buckling was not started until mid of 1980s. The first analytical model for describing the distortional buckling of CFS sections was developed by Lau and Hancock in 1987 [2] for columns subjected to axial compression. Later, this model was extended by Hancock [3] to CFS beams subjected to bending. In Law and Hancock's model the distortional buckling was modelled by a beam comprising only the compression flange and lip with a rotational spring and a translational spring applied at the compression flange-web junction. By using the flexural-torsional buckling theory of undistorted thin-walled columns developed by Timoshenko and Gere (1961) [4] and Vlasov (1961) [5], the critical buckling stress of the compression flange and lip can be calculated. The prettiness of the model is that 
the critical stress of distortional buckling can be obtained analytically, although the formula is complicated. The shortcoming is the formula that requires the determination of rotational spring constant and the stress interaction between the compression flange and web. The former has been discussed by Jiang and Davies [6], who investigated the effect of the rotational spring constant on the critical stress of distortional buckling of CFS beams, in which the rotational spring stiffness was obtained by assuming the tension end of the web to be pinned instead of fixed as originally suggested in Hancock's model. Li and Chen [7] also modified the Law and Hancock's model by taking account the flexural ability of the compression flange. $\mathrm{Li}$ and Chen used a vertical spring applied at the centroid of the compression flange and lip system to replace the rotational spring at the web-flange junction, which leads to a reduced critical buckling stress. Interestingly, the reduction fact obtained by using the vertical spring in $\mathrm{Li}$ and Chen's model is very much similar to the artificial reduction factor employed in Law and Hancock's model. Li and Chen's modified model has been further extended to analyse the distortional buckling of CFS section beams under transverse loading with moment gradient along the longitudinal axis of the beams [8].

The second analytical model for analysing the distortional buckling of CFS sections was presented in Eurocode 3 (EN1993-1-3, 2006) [9], which was developed based on the compression buckling of a beam on an elastic foundation. In this model, a beam, which comprises the effective lengths of the lip and half flange adjacent to the lip, on an elastic foundation was used to represent the distortional buckling behaviour of the CFS section. The key in the model is the elastic foundation that reflects the restraint of the rest part of the section on the beam when it buckles. Li [10] examined the effect of the stiffness of the elastic foundation on the critical stress by using different web support conditions. It was shown that, the most appropriate support condition for achieving good results in Eurocode 3 is when a fixed support on the tension end of the web and a roller support on the compression end of the web are used. This finding illustrates the potential effects of stiffened folds in the web on the distortional buckling of the compression flange and lip system. It should be pointed out that, the mathematical expression for calculating the critical stress of distortional buckling is much simpler in Eurocode 3 than in any other analytical models. However, in terms of the accuracy of the obtained critical stress the Eurocode 3 is not as good as the other analytical models. This was demonstrated by a detailed comparison of critical stresses of distortional buckling obtained from various different methods for a wide range of CFS zed- and channelsections [11].

In addition to the analytical models mentioned above, numerical methods such as the finite strip method [12-18], finite element method [19-21], generalized beam theory (GBT) [22-26], neural network [27-29] and experimental methods [30-32] have also been used to analyse the distortional buckling of CFS columns and beams. An exhaustive review of these works is beyond our scope since the research in the present paper is to focus on the analytical modelling of distortional buckling of CFS beams. The paper is organised as follows. In the section two the key features of the distortional buckling of CFS zed-and channel-sections are reviewed. By the examination of the modes of distortional buckling a stiffened plate buckling model is proposed. In section three, an analytical solution of the critical buckling stress of the proposed stiffened plate is derived by using the classical principle of total potential energy. The validation of the proposed model is explained in section four, where the critical stresses of distortional buckling of CFS channel-sections obtained by using the finite strip method are compared with the critical buckling stresses calculated from the proposed stiffened plate model. The main findings of the study are presented in the conclusion section. 


\section{Overview of distortional buckling modes}

It is known that the distortional buckling mainly occurs in the structural members of open cross sections. Its buckling mode usually involves both translation and rotation at the sectional fold lines of a member leading to a distortion of the cross section. The halfwavelength of the distortional buckling mode is typically several times larger than the largest characteristic dimension of the cross-section. Figure 1 shows the typical buckling curves of a zed-section and a channel-section under a pure bending about their major axis, obtained by using the finite strip analysis program (CUFSM Version 2.6) developed originally by Schafer. For each section there are two buckling curves that are plotted in the figure; the case one is when the tension end of the web is completely free and the case two is when the tension end of the web is rotationally fixed. It can be seen from the figure that, for both sections the rotational restraint applied at the tension end of the web has little influence on the local and distortional buckling of the sections. Table 1 gives a comparison of the lowest critical stresses of the distortional buckling of the un-restrained and restrained zed- and channel-sections. It is found that the difference in terms of the lowest critical stress between the un-restrained and restrained sections is less than $4.3 \%$. Also, it is observed from the figure that the buckling curves of the zed-section are almost the same as those of the channel section. This indicates that the distortional buckling of the CFS zed- and channel-section beams under bending about their major axis can be modelled by a system comprising the web and the compression flange and lip, while the tension flange and lip can be ignored if the tension end of the web is assumed to be fixed in the system.

\section{Two-parameter stiffened plate buckling model}

As described above, during the distortional buckling the web line deflects laterally, behaving like a cantilever beam. The compression flange and lip lines behave as a 'rigid body' to follow the translation and rotation of the compression end of the web, as shown in Figure 2. Hence, the web can be treated as a plate, whereas the compression flange and lip can be modelled together as an angle stiffener. The whole system can be treated as a plate with an angle stiffener.

Let $x$ be the longitudinal axis of the beam, $y$ and $z$ are the cross-section axes, which are parallel to web and flange lines, respectively, $w(x)$ and $\theta(x)$ be the lateral displacement and angle of rotation at the compression end of the web (see Figure 2). Thus the deflection of the web plate can be expressed as follows:

$$
w_{p}(x, y)=N_{1}(y) w-N_{2}(y) \theta
$$

where $w_{p}(x, y)$ is the deflection function of web plate, $N_{l}(y)$ and $N_{2}(y)$ are the interpolation functions, defined as follows,

$$
\begin{aligned}
& N_{1}(y)=1-3\left(\frac{y}{h}\right)^{2}+2\left(\frac{y}{h}\right)^{3} \\
& N_{2}(y)=h\left[\frac{y}{h}-2\left(\frac{y}{h}\right)^{2}+\left(\frac{y}{h}\right)^{3}\right]
\end{aligned}
$$

where $h$ is the web depth. The shear centre of the angle stiffener is at the flange/lip junction, where the displacements can be expressed as follows, 


$$
\begin{aligned}
& v_{s}(x)=b \theta \\
& w_{s}(x)=w \\
& \phi_{s}(x)=\theta
\end{aligned}
$$

where $v_{s}(x)$ and $w_{s}(x)$ are the vertical and lateral deflections of the stiffener, $\phi_{s}(x)$ is the angle of twist of the stiffener, and $b$ is the flange width.

Note that, during the distortional buckling neither the web plate nor the angle stiffener is bent about their own centroid axis because of the compatibility requirement of the longitudinal displacement at the web/flange joint point. This means that, apart from the bending about the midlines of the plate and the centroid axes of the stiffener, the plate and stiffener may also have the longitudinal displacements on the midlines of the plate and at the centroid point of the stiffener. The distribution of axial strain in a stiffened plate with asymmetric stiffeners has been reported in literature [33-35], but the assumptions used are not consistent. For example, Rothwell [33] assumed a strain distribution for the sideway bending of the stiffener, which went to zero at the joint between the plate and stiffener; whereas Hughes and Ma [35] assumed the strain distribution for the sideway bending of the stiffener was uniform in the plate. In order to examine the axial strain distribution in the distortional buckling mode, the finite strip analysis of a channel-section beam subjected to pure bending about its major axis has been performed. Figure 3 shows the axial displacement distribution of the distortional buckling mode along the lip-flange-web-flange-lip midlines. In the two curves shown in Figure $3 \mathrm{a}$, one is not modified, in which the axial displacement is caused by both the side and vertical bendings of the stiffener; the other is modified in the finite strip analysis by restraining the lateral movement of the compression flange/web junction, in which the axial displacement is caused only by the side bending of the stiffener. In the two curves shown in Figure $3 b$, one represents the axial displacement caused by the side bending alone, which is the same as that shown in Figure 3a, whereas the other represents the axial displacement caused by the vertical bending alone, which is obtained by the difference of the two curves shown in Figure $3 \mathrm{a}$. It can be seen from Figure $3 \mathrm{~b}$ that, for the side bending of the stiffener the axial displacement varies linearly from a positive value to a negative value in the lip, keeps almost constant in the flange, and then reduces almost linearly from the compression end to the tension end of the web. For the vertical bending of the stiffener, the axial displacement is constant in the lip, varies linearly in the flange, and then reduces almost linearly from the compression end to the tension end of the web. Although there are some axial displacements in the tension lip and flange, their values are very small. Based on the finding of the axial displacement distributions, an approach for the axial strain distributions generated by the side and vertical bending is thus proposed herein, which is shown in Figure 4. Note that in the above discussion the axial strain or axial displacement caused by the twist of the stiffener is not considered. This is because the stiffener considered here is an angle stiffener for which the warping effect can be generally ignored.

According to the axial strain distribution proposed in Figure 4, the position of the bending centre of the stiffened plate thus can be obtained as follows,

$$
\begin{aligned}
& y_{o}=\frac{c^{2}}{2 b+2 c+h} \\
& z_{o}=\frac{b(b+2 c)}{2 b+2 c+h}
\end{aligned}
$$

where $y_{o}$ and $z_{o}$ are the coordinates of the bending centre and $c$ is the lip length. 
The strain energy of the web plate and the stiffener can be calculated as follows,

$$
\begin{aligned}
U_{p} & =\frac{D}{2} \int_{o}^{l} \int_{o}^{h}\left[\left(\frac{\partial^{2} w_{p}}{\partial x^{2}}+\frac{\partial^{2} w_{p}}{\partial y^{2}}\right)^{2}+2(1-v)\left(\left(\frac{\partial^{2} w_{p}}{\partial x \partial y}\right)^{2}-\frac{\partial^{2} w_{p}}{\partial x^{2}} \frac{\partial^{2} w_{p}}{\partial y^{2}}\right)\right] d x d y \\
& +\frac{E h t}{6} \int_{o}^{l}\left[\left(z_{o} \frac{\partial^{2} w_{s}}{\partial x^{2}}\right)^{2}+\left(y_{o} \frac{\partial^{2} v_{s}}{\partial x^{2}}\right)^{2}\right] d x \\
U_{s} & =\frac{1}{2} \int_{o}^{l}\left[E I_{y}\left(\frac{d^{2} w_{s}}{d x^{2}}\right)^{2}+2 E I_{y z} \frac{d^{2} v_{s}}{d x^{2}} \frac{d^{2} w_{s}}{d x^{2}}+E I_{z}\left(\frac{d^{2} v_{s}}{d x^{2}}\right)^{2}+G J\left(\frac{d \phi_{s}}{d x}\right)^{2}\right] d x
\end{aligned}
$$

where $U_{p}$ and $U_{S}$ are the strain energy of the web plate and angle stiffener, respectively, $D=\frac{E t^{3}}{12\left(1-v^{2}\right)}$ is the flexural rigidity of the web plate, $E$ is the Young's modulus, $v$ is the

Poisson's ratio, $t$ is the thickness, $I_{y}$ and $I_{z}$ are the second moments of area of the stiffener about $y$ - and $z$-axes defined at bending centre, $I_{y z}$ is the corresponding product moment of area of the stiffener, $G$ is the shear modulus, $J$ is the torsion constant, and $l$ is the beam length. The first integration in Eq. (9) is the bending strain energy of the web plate, whereas the second one is the membrane strain energy of the web plate. The moments and product moment of area of the stiffener are calculated as follows,

$$
\begin{aligned}
& I_{y}=\frac{c t^{3}}{12}+c t\left(b-z_{o}\right)^{2}+\frac{t b^{3}}{12}+b t\left(\frac{b}{2}-z_{o}\right)^{2} \\
& I_{z}=\frac{t c^{3}}{12}+c t\left(\frac{c}{2}-y_{o}\right)^{2}+\frac{b t^{3}}{12}+b t y_{o}^{2} \\
& I_{y z}=c t\left(\frac{c}{2}-y_{o}\right)\left(b-z_{o}\right)-b t y_{o}\left(\frac{b}{2}-z_{o}\right) \\
& J=\frac{(c+b) t^{3}}{3}
\end{aligned}
$$

The lateral displacement and angle of rotation at the compression end point of the web can be assumed as follows,

$$
\begin{aligned}
& w(x)=\sum_{k=1} A_{k} \sin \frac{k \pi x}{l} \\
& \theta(x)=\sum_{k=1} B_{k} \sin \frac{k \pi x}{l}
\end{aligned}
$$

where $A_{k}$ and $B_{k}$ are the constants, and $k$ is the number of half waves. Substituting Eqs. (15) and (16) into (1), (4)-(6) and then into (9) and (10), it yields,

$$
U_{p}=\frac{D l}{4} \sum_{k=1}\left(\frac{k \pi}{l}\right)^{2}\left\{\begin{array}{l}
{\left[\frac{13 h}{35}\left(\frac{k \pi}{l}\right)^{2}+\frac{12}{5 h}+\frac{12}{h^{3}}\left(\frac{l}{k \pi}\right)^{2}\right] A_{k}^{2}+\left[\frac{h^{3}}{105}\left(\frac{k \pi}{l}\right)^{2}+\frac{4 h}{15}+\frac{4}{h}\left(\frac{l}{k \pi}\right)^{2}\right] B_{k}^{2}} \\
-\left[\frac{11 h^{2}}{105}\left(\frac{k \pi}{l}\right)^{2}+\frac{2+10 v}{5}+\frac{12}{h^{2}}\left(\frac{l}{k \pi}\right)^{2}\right] A_{k} B_{k}+\frac{E h t}{3 D}\left(\frac{k \pi}{l}\right)^{2}\left(z_{o}^{2} A_{k}^{2}+y_{o}^{2} b^{2} B_{k}^{2}\right)
\end{array}\right\}
$$


$U_{s}=\frac{E l}{4} \sum_{k=1}\left(\frac{k \pi}{l}\right)^{4}\left[I_{y} A_{k}^{2}+2 b I_{y z} A_{k} B_{k}+b^{2} I_{z} B_{k}^{2}+\frac{G J}{E}\left(\frac{l}{k \pi}\right)^{2} B_{k}^{2}\right]$

The work done by the pre-buckling axial stresses in the web plate and angle stiffener can be calculated as follows,

$$
\begin{aligned}
& W_{p}=\frac{\sigma_{c r} t}{2} \int_{o}^{l} \int_{o}^{b}\left(1-\frac{2 y}{h}\right)\left(\frac{d w_{p}}{d x}\right)^{2} d x d y \\
& W_{s}=\frac{\sigma_{c r} t}{2} \int_{o}^{l} \int_{o}^{b}\left[\left(\frac{d w}{d x}\right)^{2}+\left(z \frac{d \theta}{d x}\right)^{2}\right] d x d z+\frac{\sigma_{c r} t}{2} \int_{o}^{l} \int_{o}^{c}\left[\left(b \frac{d \theta}{d x}\right)^{2}+\left(\frac{d w}{d x}-y \frac{d \theta}{d x}\right)^{2}\right] d x d y
\end{aligned}
$$

where $\sigma_{c r}$ is the critical stress located in the compression flange when the buckling of the stiffened plate occurs. Substituting Eqs. (15) and (16) into (19) and (20), it yields,

$$
\begin{aligned}
& W_{p}=\frac{\sigma_{c r} t l}{4} \sum_{k=1}\left(\frac{k \pi}{l}\right)^{2}\left(\frac{h}{5} A_{k}^{2}+\frac{h^{3}}{420} B_{k}^{2}-\frac{4 h^{2}}{105} A_{k} B_{k}\right) \\
& W_{s}=\frac{\sigma_{c r} t l}{4} \sum_{k=1}\left(\frac{k \pi}{l}\right)^{2}\left[(b+c) A_{k}^{2}+\frac{b^{3}+3 b^{2} c+c^{3}}{3} B_{k}^{2}-c^{2} A_{k} B_{k}\right]
\end{aligned}
$$

The condition when the buckling occurs is the total potential of the system to have a stationary condition with respect to the constants $A_{k}$ and $b_{k}$. This requires the following conditions,

$$
\begin{aligned}
& \frac{\partial \Pi}{\partial A_{k}}=\frac{\partial}{\partial A_{k}}\left(U_{p}+U_{s}-W_{p}-W_{s}\right)=0 \\
& \frac{\partial \Pi}{\partial B_{k}}=\frac{\partial}{\partial B_{k}}\left(U_{p}+U_{s}-W_{p}-W_{s}\right)=0
\end{aligned}
$$

This leads to the following eigenvalue equation,

$\left\{\left[\begin{array}{ll}a_{11} & a_{12} \\ a_{21} & a_{22}\end{array}\right]-\sigma_{c r} t\left[\begin{array}{ll}b_{11} & b_{12} \\ b_{21} & b_{22}\end{array}\right]\right\}\left\{\begin{array}{l}A_{k} \\ B_{k}\end{array}\right\}=\left\{\begin{array}{l}0 \\ 0\end{array}\right\}$

in which,

$$
\begin{aligned}
& a_{11}=\frac{D}{h}\left[\frac{13 h^{2}}{35}\left(\frac{k \pi}{l}\right)^{2}+\frac{12}{5}+\frac{12}{h^{2}}\left(\frac{l}{k \pi}\right)^{2}\right]+E\left(\frac{k \pi}{l}\right)^{2}\left(I_{y}+\frac{h t z_{o}^{2}}{3}\right) \\
& a_{12}=a_{21}=-D\left[\frac{11 h^{2}}{210}\left(\frac{k \pi}{l}\right)^{2}+\frac{1+5 v}{5}+\frac{6}{h^{2}}\left(\frac{l}{k \pi}\right)^{2}\right]+E b\left(\frac{k \pi}{l}\right)^{2} I_{y z} \\
& a_{22}=D h\left[\frac{h^{2}}{105}\left(\frac{k \pi}{l}\right)^{2}+\frac{4}{15}+\frac{4}{h^{2}}\left(\frac{l}{k \pi}\right)^{2}\right]+E b^{2}\left[\left(I_{z}+\frac{h t y_{o}^{2}}{3}\right)\left(\frac{k \pi}{l}\right)^{2}+\frac{G J}{E b^{2}}\right]
\end{aligned}
$$




$$
\begin{aligned}
& b_{11}=\frac{h}{5}+b+c \\
& b_{12}=b_{21}=-\left(\frac{2 h^{2}}{105}+\frac{c^{2}}{2}\right) \\
& b_{22}=\frac{h^{3}}{420}+\frac{b^{3}+3 b^{2} c+c^{3}}{3}
\end{aligned}
$$

Eq. (25) is a $2 \times 2$ eigenvalue equation. The critical stress $\sigma_{c r}$ of the stiffened plate can be solved from Eq. (25) analytically. Note that if the half wavelength is equal to the beam length then $k=1$ and $\sigma_{c r, 1}$ is the critical stress. Otherwise the critical stress should be taken as the smallest one from all calculated wave numbers $(k=1,2, \ldots, N)$. In this case if $\sigma_{c r, k}$ is the smallest one, then $l / k$ is the corresponding half wavelength.

\section{Validation of the model}

In order to validate the present stiffened plate buckling model (SPBM), Figure 5 shows a detailed comparison of buckling curves obtained from the present model and those obtained from the finite strip method (FSM) for three typical CFS channel-section beams with web tension end being rotationally restrained. These three sections represent the small, medium and deep sections, respectively. It can be seen from the figure that the critical stress predicted by SPBM is consistently higher than that calculated from FSM. However, in terms of the lowest critical stress which is to be used in design, the difference between the two models is only marginal. Also, it can be observed from the figure that, the larger the section, the smaller the difference between the two models. The reason for this is partly because the deflection function employed for the web plate involves only two degrees of freedom, and partly because the use of the stiffener model for the flange and lip; both make the web-flange-lip system stiffer and thus yields higher critical buckling stress. It also should be pointed out here that the FSM results shown in Figure 5 are for the beam with the web tension end being rotationally restrained. If there is no rotational restraint at the tension end of the web, the critical stress calculated from FSM will be even smaller, thus leading to a more diverse of the predicted critical stresses from the FSM results.

In order to compensate the effects from both the rotational restraint used in developing the stiffened plate model and the simplified deflection functions used in calculating the potential energy, a section size-based reduction factor, $\alpha=[h+3(b+c) / 5] /(h+b+c)$, is introduced in the critical stress calculated from the present model. This reduction factor reflects the relative flexural ability of the web, flange and lip. Figure 6 shows a comprehensive comparison of the critical stresses of distortional buckling of 59 channel-section beams (see Table 2) obtained by using FSM and SPBM. The sections examined here are manufactured by Albion Sections in the UK. In Figure 6, the critical stress plotted on the x-axis is the distortional buckling stress obtained from FSM for the channel-section with no any restraint, whereas the critical stress plotted on the y-axis is predicted by using Eq. (25) with applying the reduction factor $\alpha$. Thus any point below the line of slope unity implies that the critical stress is underpredicted, and vice versa. It is evident from the figure that, the reduced critical stresses in the present model are in exceptionally good agreement with those calculated from the finite strip analysis. 
Most purlins in practice are used to support roof sheeting. In the action of the gravity loading, the purlin can be assumed to be laterally restrained at the compression end of the web. In this case, the lateral displacement $w$ is zero (i.e. $A_{k}=0$ ) and thus the critical stress of distortional buckling shown in Eq. (25) can be simplified as follows,

$$
\sigma_{c r}=\alpha \cdot \frac{a_{22}}{t b_{22}}=\frac{h+\frac{3(b+c)}{5}}{h+b+c} \times \frac{D\left[\left(\frac{k \pi}{l}\right)^{2}\left(\frac{h^{3}}{105}+\frac{E b^{2}}{D}\left(I_{z}+\frac{h t y_{o}^{2}}{3}\right)\right)+\frac{4}{h}\left(\frac{l}{k \pi}\right)^{2}+\frac{4 h}{15}+\frac{G J}{D}\right]}{t\left(\frac{h^{3}}{420}+\frac{b^{3}+3 b^{2} c+c^{3}}{3}\right)}
$$

Eq. (26) can be interpreted based on the energy balance. The term $a_{22}$ represents the strain energy generated by the unit angle of rotation; whereas the term $b_{22}$ is the change of potential of the pre-buckling stress for the same angle of rotation. The displacements assumed in the stiffened plate model may be accurate for deep sections but not for shallow sections. In the latter the flange may also be bent [7]. The assumption of "a stiffener" implies that the flange and lip may be treated to be too stiff. Thus, from the point of view of energy the strain energy of the stiffener is overestimated, while the corresponding displacement is underestimated. This leads to " $a_{22} / b_{22}$ " to be overestimated. The reduction factor $\alpha$ is used to compensate this "enlarging" effect caused in energy by the displacement functions assumed. As the section becomes deeper, the "enlarging" effect becomes smaller, and $\alpha$ is closer to 1 . This is why for a deep section where $h>>(b+c), \alpha \rightarrow 1$.

The half wavelength corresponding to the smallest critical stress in Eq. (26) can be obtained by applying the limiting condition of $\mathrm{d} \sigma_{c r} / \mathrm{d}(l / k)=0$, which yields

$$
\left(\frac{l}{k}\right)^{2}=\frac{\pi^{2} h}{2} \sqrt{\left(\frac{h^{2}}{105}+\frac{E b^{2}}{D h}\left(I_{z}+\frac{h t y_{o}^{2}}{3}\right)\right)}
$$

Substituting Eq. (27) into (26), it yields,

$$
\sigma_{c r, \text { min }}=\frac{h+\frac{3(b+c)}{5}}{h+b+c} \times \frac{4 D\left[\sqrt{\frac{h^{2}}{105}+\frac{E b^{2}}{D h}\left(I_{z}+\frac{h t y_{o}^{2}}{3}\right)}+\frac{h}{15}+\frac{G J}{4 D}\right]}{t\left(\frac{h^{3}}{420}+\frac{b^{3}+3 b^{2} c+c^{3}}{3}\right)}
$$

Figure 7 shows the comparison of the critical stress calculated from Eq. (28) and that predicted using FSM for the 59 channel-section beams (see Table 2) for the case where the lateral displacement at the compression end of the web is restrained. Again excellent agreement between the present model and FSM is demonstrated. This confirms that the stiffened plate buckling model proposed herein is able to catch the main features of the distortional buckling of CFS zed- and channel-section beams, and after the proposed reduction factor is applied the model can provide accurate critical stress of distortional buckling of CFS section beams.

\section{Conclusions}


This paper has presented a stiffened plate buckling model for describing the distortional buckling of CFS zed- and channel-section beams when they are bent about their major axis. Two analytical formulae have been derived for calculating the critical stress of distortional buckling; one is for the beam without any restraint and the other is for the beam with lateral displacement restraint at the compression end of the web representing the effect of sheeting on the beam. In both cases the critical stresses calculated from the present model have been validated by using the finite strip analysis. From the present study the following conclusions can be drawn:

- For the distortional buckling of CFS zed- and channel-section beams the web can be treated as a plate and the compression flange and lip can be modelled as stiffener of the web. While the tension flange and lip can be generally ignored when the tension end of the web is assumed to be fixed.

- During the distortional buckling, the bending centre of the stiffened plate comprising of the web, compression flange and lip is neither at the centroid point of the stiffened plate nor at the centroid point of the section. Thus, apart from their bending strain energy, the membrane strain energy of the web as a plate, and flange and lip as a stiffener must also be considered.

- Owing to the use of the fixed boundary condition at the tension end of the web and the two-parameter deflection function for the web, as well as the stiffener assumption, the critical stress calculated from the stiffened plate buckling model is marginally overestimated, particularly for small sections. However, this overestimation can be compensated by the use of the proposed section size-based reduction factor.

- Excellent agreement between the proposed two formulae and the finite strip analyses has been demonstrated for a wide range of CFS channel-sections used in the UK market.

Acknowledgements - The authors acknowledge the financial support received from National Natural Science Foundation of China (No.11572162). The first author also wishes to acknowledge the $47^{\text {th }}$ Scientific Research Foundation for Returned Scholars from Ministry of Education of China, Natural Science Foundation of Zhejiang Province (No.LY13A020007), and K.C. Wong Magna Fund at Ningbo University for their financial support.

\section{References}

[1] Hancock GJ. Local, distortional and lateral buckling of I-beams. Journal of Structural Division ASCE 1978; 104(11): 1787-1798.

[2] Lau SCW, Hancock GJ. Distortional buckling formulas for channel columns. Journal of Structural Engineering, ASCE 1987; 113: 1063-1078.

[3] Hancock GJ. Design for distortional buckling of flexural members. Thin-Walled Structures 1997; 27(1): 3-12.

[4] Timoshenko SP, Gere JM. Theory of Elastic Stability, 1961, McGraw Hill, New York.

[5] Vlasov VZ. Thin-walled Elastic Beams, 1961, Translated by Israel Program for Scientific Translation for National Science Foundation, Washington D.C. 
[6] Jiang C, Davies JM. Design of thin-walled purlins for distortional buckling. Thin-Walled Structures 1997; 29(1-4): 189-202.

[7] Li LY, Chen JK. An analytical model for analysing distortional buckling of cold-formed steel sections. Thin-Walled Structures 2008; 46(12): 1430-1436.

[8] Chen JK, Li LY. Distortional buckling of cold-formed steel sections subjected to uniformly distributed transverse loading, International Journal of Structural Stability and Dynamics 2010; 10(5): 1017-1030.

[9] EN1993-1-3. Eurocode 3 - Design of Steel Structures - Part 1-3: General rules Supplementary rules for cold-formed members and sheeting. 2006, BSI.

[10] Li LY. Analyses of distortional buckling of cold-formed sigma purlins using EN1993-13. Journal of Constructional Steel Research 2009; 65(12): 2099-2102.

[11] Li LY. Calculation of moment capacity of cold-formed steel members. International Journal of Structural Engineering 2011; 2(2): 101-115

[12] Lau SCW, Hancock GJ. Buckling of thin flat-walled structures by a spline finite strip method. Thin-Walled Structures 1986; 4(4): 269-294.

[13] Schafer BW, Li Z, Moen CD. Computational modelling of cold-formed steel. ThinWalled Structures 2010; 48(10-11): 752-762.

[14] Chu XT, Ye ZM, Kettle R, Li LY. Buckling behaviour of cold-formed channel sections under uniformly distributed loads. Thin-Walled Structures 2005; 43(4): 531-542.

[15] Chu XT, Ye ZM, Li LY, Kettle R. Local and distortional buckling of cold-formed zedsection beams under uniformly distributed transverse loads. International Journal of Mechanical Sciences 2006; 48(4): 378-388.

[16] Yuan WB, Cheng SS, Li LY, Kim B. Web-flange distortional buckling of partially restrained cold-formed steel purlins under uplift loading, International Journal of Mechanical Sciences 2014; 89: 476-481.

[17] Dong S, Li HR, Wen QP. Study on distortional buckling performance of cold-formed thin-walled steel flexural members with stiffeners in the flange. Thin-Walled Structures 2015; 95: 161-169,

[18] Naderian HR, Ronagh HR, Azhari M. Elastic distortional buckling of doubly symmetric steel I-section beams with slender webs. Thin-Walled Structures 2014; 84: 289-301.

[19] Casafont M, Marimon F, Pastor MM. Calculation of pure distortional elastic buckling loads of members subjected to compression via the finite element method. Thin-Walled Structures 2009; 47(6-7): 701-729.

[20] Haidarali MR, Nethercot DA. Local and distortional buckling of cold-formed steel beams with both edge and intermediate stiffeners in their compression flanges. Thin-Walled Structures 2012; 54: 106-112.

[21] Niu S, Rasmussen KJR, Fan F. Distortional-global interaction buckling of stainless steel C-beams: Part II-Numerical study and design. Journal of Constructional Steel Research 2014; 96: 40-53.

[22] Davis JM, Leach P. First-order generalized beam theory. Journal of Constructional Steel Research 1994; 31(2/3): 187-220.

[23] Davis JM, Leach P. Second-order generalized beam theory. Journal of Constructional Steel Research 1994; 31(2/3): 221-241.

[24] Schardt R. Lateral torsional and distortional buckling of channel- and hat-sections. Journal of Constructional Steel Research 1994; 31(2-3): 243-265.

[25] Silvestre N, Camotim D. Distortional buckling formulae for cold-formed steel c- and zsection members. Part I - derivation. Thin-Walled Structures 2004; 42(11): 1599-1629.

[26] Luo HG, Guo YJ, Ma SC. Distortional buckling of thin-walled inclined lipped channel beams bending about the minor axis. Journal of Constructional Steel Research 2011; 67(12): 1884-1889. 
[27] Pala M. A new formulation for distortional buckling stress in cold-formed steel members. Journal of Constructional Steel Research 2006; 62(7): 716-722.

[28] Pala M, Caglar N. A parametric study for distortional buckling stress on cold-formed steel using a neural network. Journal of Constructional Steel Research 2007; 63(5): 686-691.

[29] Pala M. Genetic programming-based formulation for distortional buckling stress of coldformed steel members. Journal of Constructional Steel Research 2008; 64(12): 1495-1504.

[30] Casafont M, Pastor MM, Roure F, Peköz T. An experimental investigation of distortional buckling of steel storage rack columns. Thin-Walled Structures 2011; 49(8): 933946.

[31] dos Santos ES, Batista EM, Camotim D. Experimental investigation concerning lipped channel columns undergoing local-distortional-global buckling mode interaction. ThinWalled Structures 2012; 54: 19-34.

[32] Niu S, Rasmussen KJR, Fan F. Distortional-global interaction buckling of stainless steel C-beams: Part I - Experimental investigation. Journal of Constructional Steel Research 2014; 96: 127-139.

[33] Rothwell A. Coupled modes in the buckling of panels with z-section stringers in compression. Aeronaut. J. R. Aeronaut. Soc. 1968; 72: 159-163.

[34] van der Neut A. Overall buckling of z-stiffened panels in compression. In: Collapse the Buckling of Structures in Theory and Practice (edited by JMT Thompson and GW Hunt), Canbridge University Press, London, pp.259-268.

[35] Hughes OF, Ma M. Elastic tripping analysis of asymmetrical stiffeners. Computers and Structures 1996; 60(3): 369-389. 


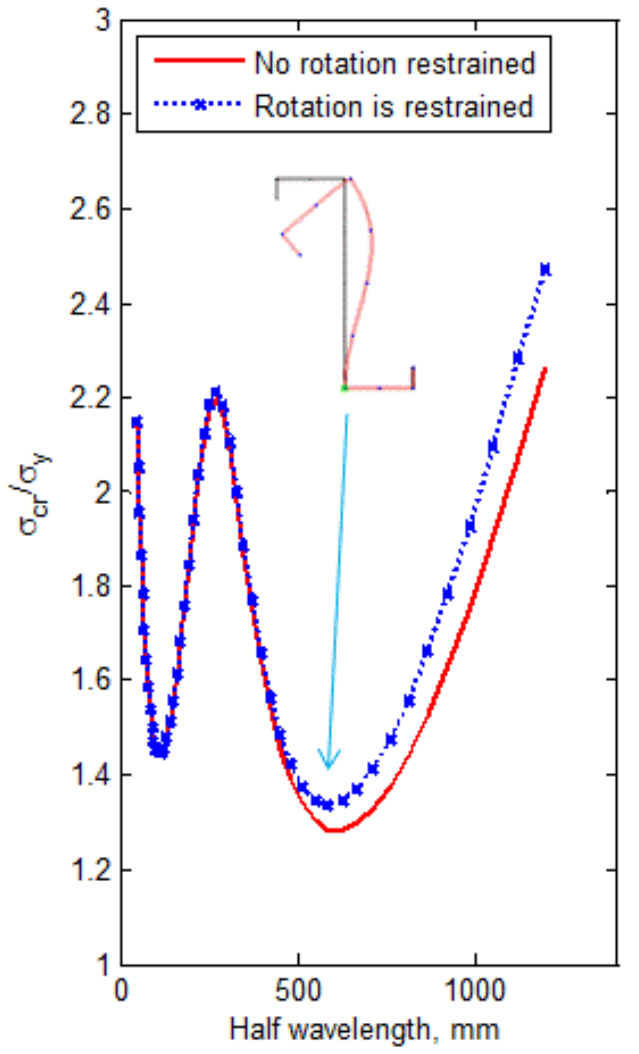

(a)

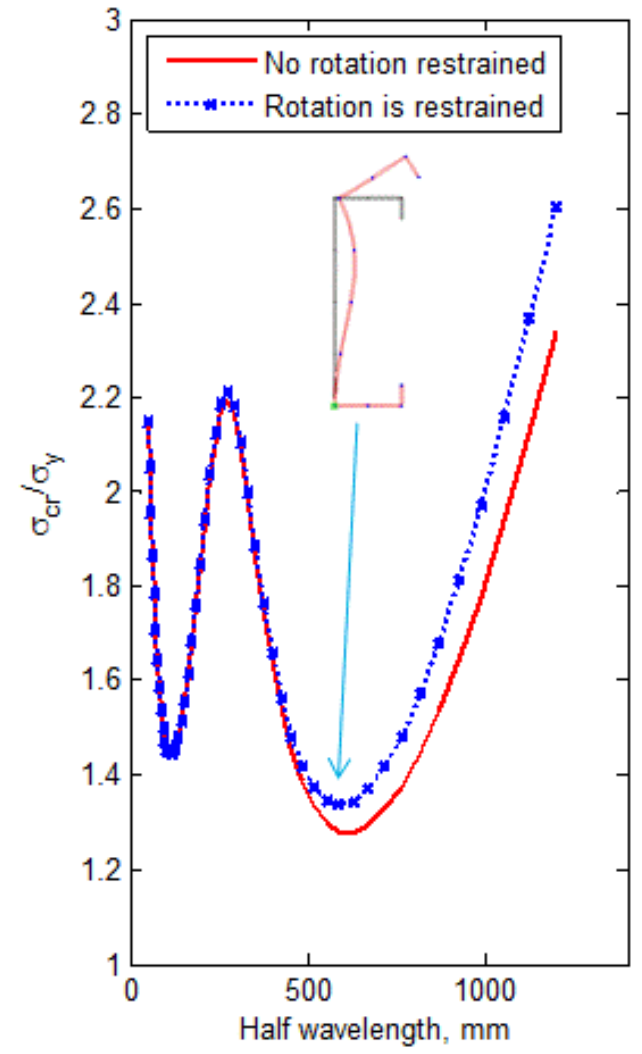

(b)

Figure 1. Distortional buckling curves. (a) zed-section under pure bending and (b) channelsection under pure bending (web depth $h=200 \mathrm{~mm}$, flange width $b=65 \mathrm{~mm}$, lip length $c=$ $20 \mathrm{~mm}$, thickness $t=2.0 \mathrm{~mm}$, yield strength $\sigma_{y}=390 \mathrm{MPa}$ ).

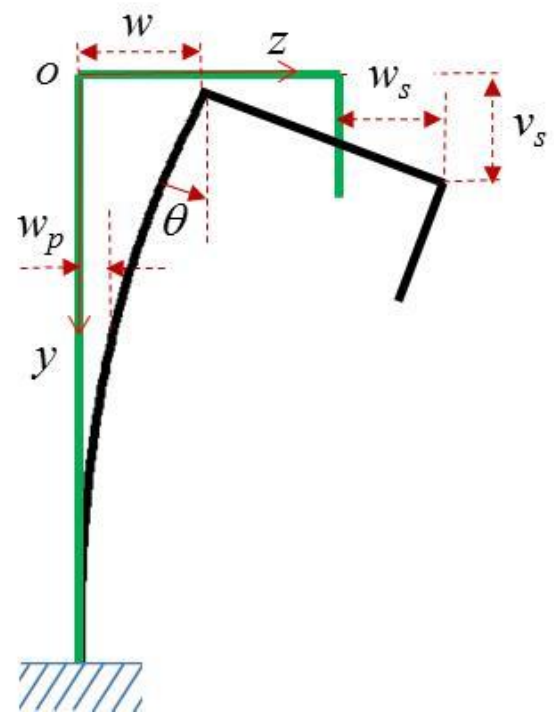

Figure 2. A two-parameter $(w, \theta)$ stiffened plate buckling model. 


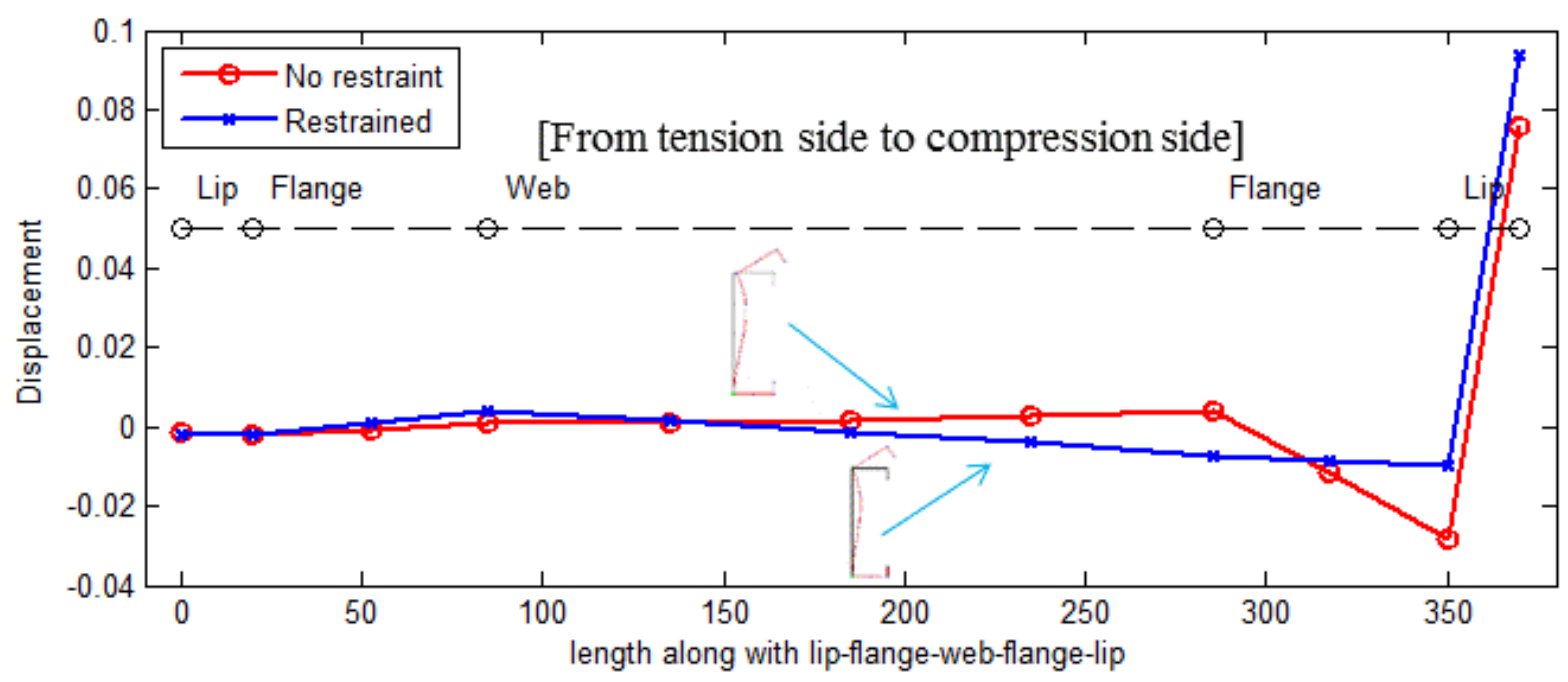

(a)

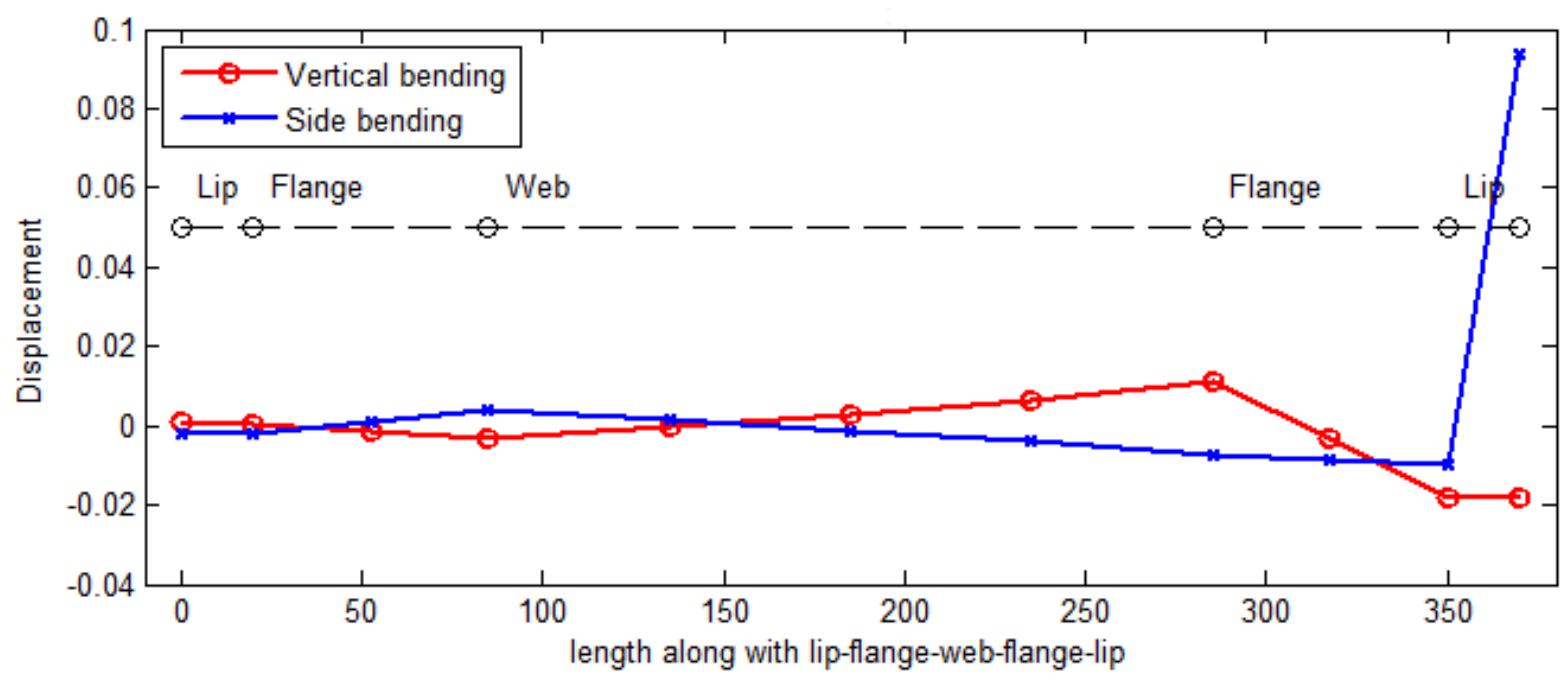

(b)

Figure 3. Distribution of the axial-component of distortional buckling displacement along the lips, flanges and web (all units in $\mathrm{mm}$ ) $(h=200 \mathrm{~mm}, b=65 \mathrm{~mm}, c=20 \mathrm{~mm}, t=2.0 \mathrm{~mm})$. 


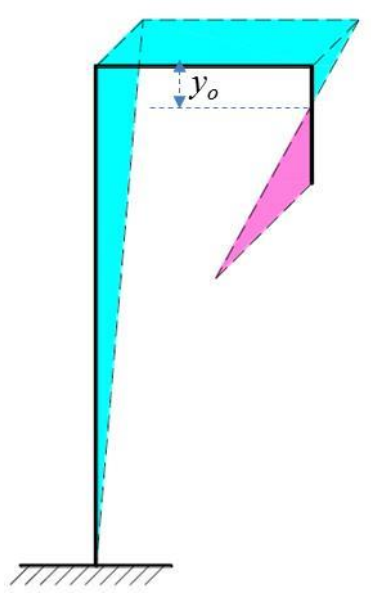

(a)

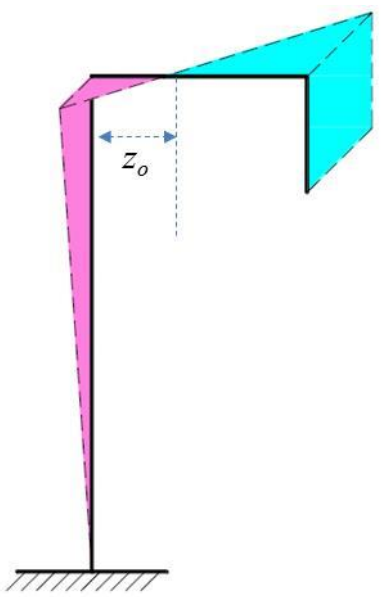

(b)

Figure 4. Proposed axial strain distributions. (a) Side bending. (b) Vertical bending.

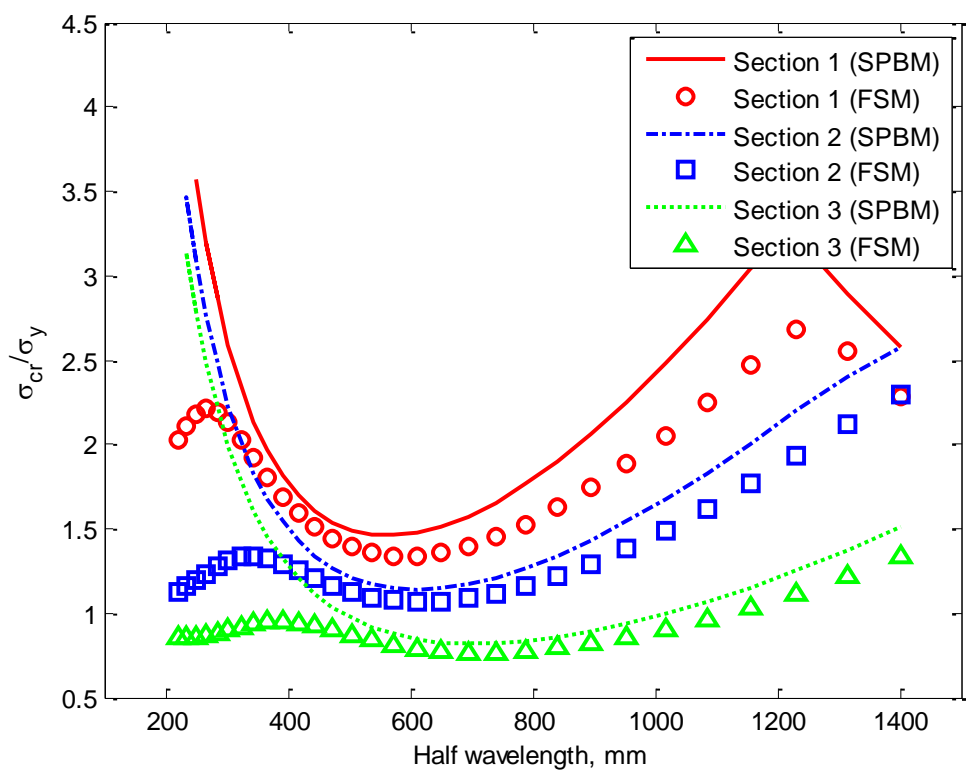

Figure 5. Distortional buckling covers. (Section 1: $h=200, b=65, c=20, t=2$. Section 2: $h$ $=300, b=75, c=20, t=2.5$. Section 3: $h=400, b=100, c=30, t=3$. All units are in mm). 


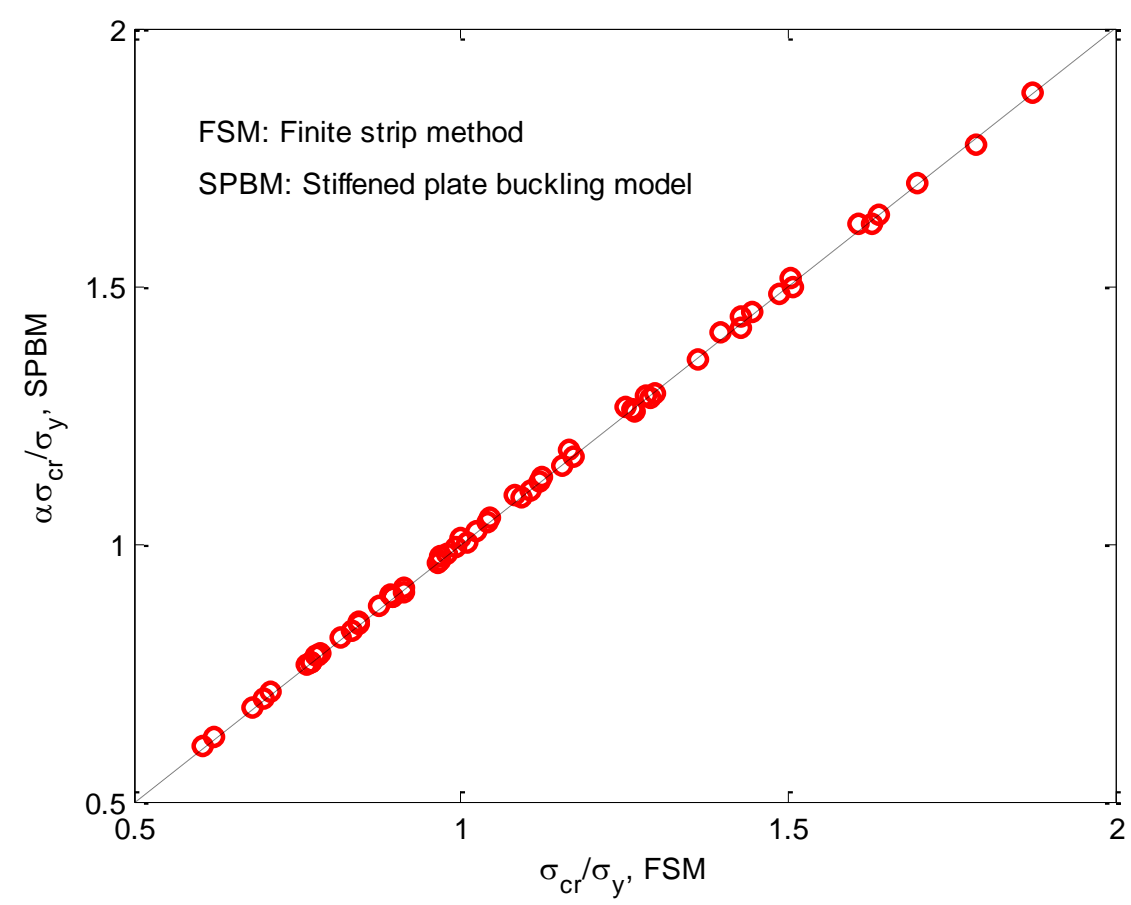

Figure 6. Comparison of critical stresses of distortional buckling of CFS channel-sections made by Albion Sections in the UK (dimensions are provided in Table 2, $\sigma_{y}=390 \mathrm{MPa}$ ).

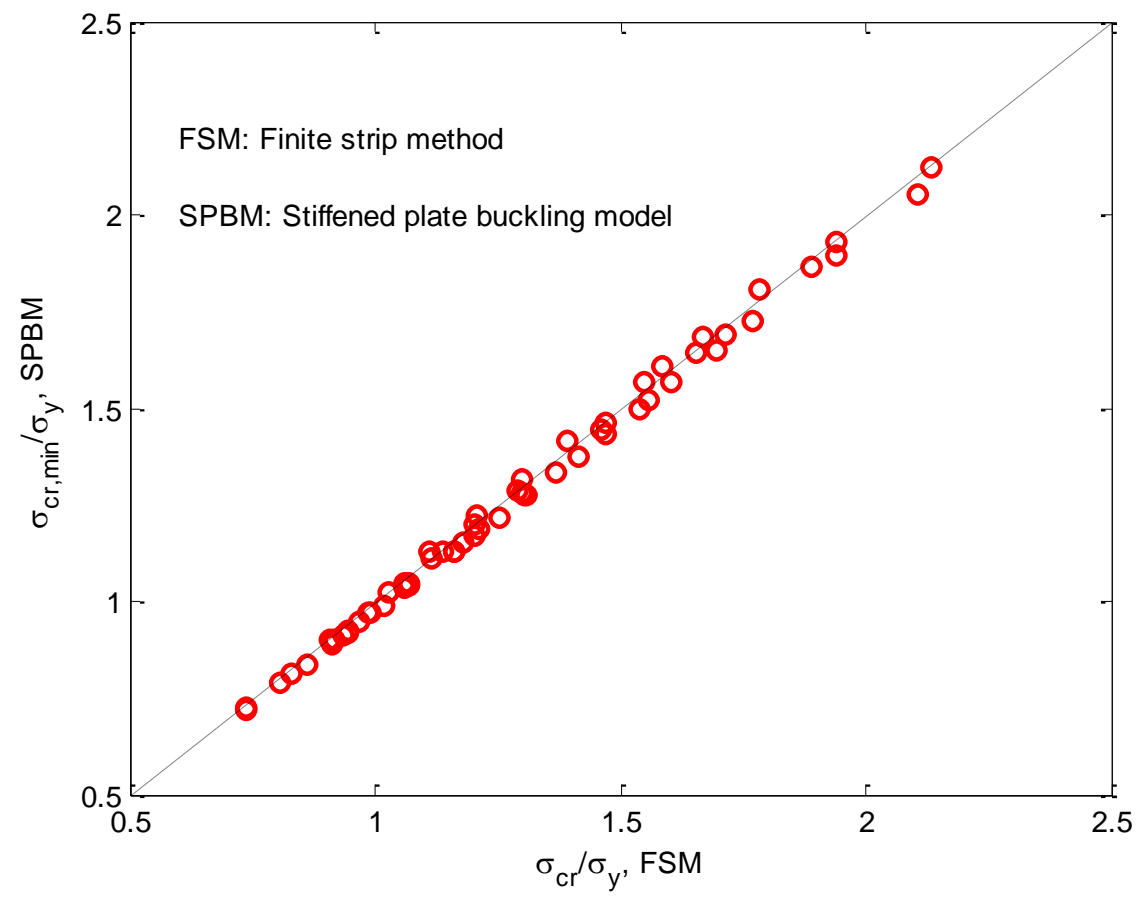

Figure 7. Comparison of critical stresses of distortional buckling of CFS channel-sections when the lateral displacement at the compression end of the web is restrained (dimensions are provided in Table 2, $\sigma_{y}=390 \mathrm{MPa}$ ). 
Table 1. Critical stresses of distortional buckling of zed- and channel-sections (web depth $h=$ $200 \mathrm{~mm}$, flange width $b=65 \mathrm{~mm}$, lip length $c=20 \mathrm{~mm}$, thickness $t=2.0 \mathrm{~mm}$, yield strength $\sigma_{y}=390 \mathrm{MPa}$, half wavelength $\lambda=600 \mathrm{~mm}$ ).

\begin{tabular}{|c|c|c|c|}
\hline Section & $\sigma_{c r} / \sigma_{y}$ (No restraint) & $\sigma_{c r} \sigma_{y}($ restrained) & Effect of restraint \\
\hline Zed-section & 1.286 & 1.340 & $+4.20 \%$ \\
\hline Channel-section & 1.284 & 1.339 & $+4.28 \%$ \\
\hline
\end{tabular}

Table 2: Dimensions of CFS channel-sections produced by Albion Sections (unit: $\mathrm{mm}$ )

\begin{tabular}{|c|c|c|c|c|}
\hline Sections & Web depth, $h$ & Flange width, $b$ & Lip length, $c$ & Thickness, $t$ \\
\hline C12515 & 120 & 50 & 15 & 1.5 \\
\hline C12516 & 120 & 50 & 15 & 1.6 \\
\hline C14613 & 145 & 62.5 & 20 & 1.3 \\
\hline C14614 & 145 & 62.5 & 20 & 1.4 \\
\hline C14615 & 145 & 62.5 & 20 & 1.5 \\
\hline C14616 & 145 & 62.5 & 20 & 1.6 \\
\hline C14618 & 145 & 62.5 & 20 & 1.8 \\
\hline C14620 & 145 & 62.5 & 20 & 2.0 \\
\hline C17613 & 175 & 62.5 & 20 & 1.3 \\
\hline C17614 & 175 & 62.5 & 20 & 1.4 \\
\hline C17615 & 175 & 62.5 & 20 & 1.5 \\
\hline C17616 & 175 & 62.5 & 20 & 1.6 \\
\hline C17618 & 175 & 62.5 & 20 & 1.8 \\
\hline C17620 & 175 & 62.5 & 20 & 2.0 \\
\hline C17623 & 175 & 62.5 & 20 & 2.3 \\
\hline C17625 & 175 & 62.5 & 20 & 2.5 \\
\hline C20613 & 200 & 65 & 20 & 1.3 \\
\hline C20614 & 200 & 65 & 20 & 1.4 \\
\hline C20615 & 200 & 65 & 20 & 1.5 \\
\hline C20616 & 200 & 65 & 20 & 1.6 \\
\hline C20618 & 200 & 65 & 20 & 1.8 \\
\hline C20620 & 200 & 65 & 20 & 2.0 \\
\hline C20623 & 200 & 65 & 20 & 2.3 \\
\hline C20625 & 200 & 65 & 20 & 2.5 \\
\hline C22614 & 225 & 65 & 20 & 1.4 \\
\hline C22615 & 225 & 65 & 20 & 1.5 \\
\hline C22616 & 225 & 65 & 20 & 1.6 \\
\hline C22618 & 225 & 65 & 20 & 1.8 \\
\hline C22620 & 225 & 65 & 20 & 2.0 \\
\hline C22623 & 225 & 65 & 20 & 2.3 \\
\hline C22625 & 225 & 65 & 20 & 2.5 \\
\hline C24615 & 240 & 65 & 20 & 1.5 \\
\hline C24616 & 240 & 65 & 20 & 1.6 \\
\hline C24618 & 240 & 65 & 20 & 1.8 \\
\hline
\end{tabular}




\begin{tabular}{|c|c|c|c|c|}
\hline C24620 & 240 & 65 & 20 & 2.0 \\
\hline C24623 & 240 & 65 & 20 & 2.3 \\
\hline C24625 & 240 & 65 & 20 & 2.5 \\
\hline C24630 & 240 & 65 & 20 & 3.0 \\
\hline C26616 & 265 & 65 & 20 & 1.6 \\
\hline C26618 & 265 & 65 & 20 & 1.8 \\
\hline C26620 & 265 & 65 & 20 & 2.0 \\
\hline C26623 & 265 & 65 & 20 & 2.3 \\
\hline C26625 & 265 & 65 & 20 & 2.5 \\
\hline C26630 & 265 & 65 & 20 & 3.0 \\
\hline C30718 & 300 & 75 & 20 & 1.8 \\
\hline C30720 & 300 & 75 & 20 & 2.0 \\
\hline C30723 & 300 & 75 & 20 & 2.3 \\
\hline C30725 & 300 & 75 & 20 & 2.5 \\
\hline C30730 & 300 & 75 & 20 & 3.0 \\
\hline C34118 & 345 & 100 & 30 & 1.8 \\
\hline C34120 & 345 & 100 & 30 & 2.0 \\
\hline C34123 & 345 & 100 & 30 & 2.3 \\
\hline C34125 & 345 & 100 & 30 & 2.5 \\
\hline C34130 & 345 & 100 & 30 & 3.0 \\
\hline C40120 & 400 & 100 & 30 & 2.0 \\
\hline C40123 & 400 & 100 & 30 & 2.3 \\
\hline C40125 & 400 & 100 & 30 & 2.5 \\
\hline C40130 & 400 & 100 & 30 & 3.0 \\
\hline C40132 & 400 & 100 & 30 & 3.2 \\
\hline
\end{tabular}

